Loading

The Journal of the Canadian Game Studies Association

[0.1DTika...

\title{
Better living through chems: Fallout's post-apocalyptic pharmacy
}

\section{Jason James Wallin}

Volume 12, Number 19, Winter-Spring 2019

URI: https://id.erudit.org/iderudit/1058318ar

DOI: https://doi.org/10.7202/1058318ar

See table of contents

Publisher(s)

Canadian Game Studies Association

ISSN

1923-2691 (digital)

Explore this journal

Cite this article

Wallin, J. (2019). Better living through chems: Fallout's post-apocalyptic pharmacy. Loading, 12(19). https://doi.org/10.7202/1058318ar
Article abstract

Contemporary climate change research today speculates that life as we know it is at an end (Scranton, 2015). As planetary conditions optimal to the survival of the human species are undergoing profound transformation, the question of what future awaits the human species has become both prominent and pervasive. Extending into the speculative art of video games, this post-apocalyptic mis-en-scene today constitutes something of a familiar reference point for gamers, who might find in such popular games as Left 4 Dead (2008) and Gears of War (2006) a particular speculation on survival where life as we know it encounters the destructive forces of nuclear devastation, epidemic, invasion, or any one of a myriad catastrophic scenarios now cliche in the medium. Yet, the ways that video games think survival nevertheless constitutes a speculative fulcrum on which is dramatized both "world without-us", or rather, an impersonal hostile world unremitting to the desires of 'man', and the human that might survive it (Thacker, 2011). Significant amongst such speculative games are the massive post-apocalyptic worlds of Fallout 3, Fallout: New Vegas, and Fallout 4, each of which evokes the question of how we might survive after nuclear catastrophe and its transformation of the planet into a foreboding ecology populated by mutated animals, radioactive dead-zones, loosely organized bandit hordes, and nomads foraging the resource scarce post-apocalyptic future.
This document is protected by copyright law. Use of the services of Erudit (including reproduction) is subject to its terms and conditions, which can be viewed online.

https://apropos.erudit.org/en/users/policy-on-use/ 


\title{
Better Living Through Chems: Fallout's Post- Apocalyptic Pharmacy
}

\author{
Jason J. Wallin \\ University of Alberta \\ jjwallin@ualberta.ca
}

Contemporary climate change research speculates that life as we know it is at an end (Scranton, 2015). As planetary conditions optimal to the survival of the human species are undergoing profound transformation, the question of what future awaits the human species has become both prominent and pervasive. Extending into the speculative art of video games, this post-apocalyptic mis-en-scene today constitutes something of a familiar reference point for gamers. Such popular games as Left 4 Dead (2008) and Gears of War (2006), for instance, advance a particular speculation on survival where life as we know it encounters the destructive forces of nuclear devastation, epidemic, invasion, or any one of myriad catastrophic scenarios now cliché in the medium. Yet, the ways that video games think survival nevertheless constitutes a speculative fulcrum that dramatizes a "world without-us", or rather, an impersonal hostile world unremitting to the desires of 'man', and the humans that might survive it (Thacker, 2011). Significant amongst such speculative games are the massive post-apocalyptic worlds of Fallout 3, Fallout: New Vegas, and Fallout 4. Fundamental to the post-apocalyptic world of Fallout is the problem of how we might survive after nuclear catastrophe and its transformation of the planet into a foreboding ecology hostile to human life. Populated by mutated animals, radioactive dead-zones, loosely organized bandit hordes, and nomads foraging resource scarce future, the world of Fallout becomes a speculative fulcrum for imagining both the potential extinction of the human and its survival through more-than-human becomings.

\section{Survival of the 'Fix'}

Of the varied means by which one might survive in the post-apocalyptic wastes of Fallout, this essay will concern itself with Fallout's particular dramatization of drugs and drug use as an affective mode of survival, where affect will be understood as a form of "existential appropriation" for alternative "aesthetic paradigms" (Genosko, 2002). While the question of how drugs figure as an affective vehicle of survival is not unique to the Fallout series, appearing prominently in the post-apocalyptic worlds of Bioshock (2007) and Resident Evil, this essay will demonstrate that Fallout's consideration of postapocalyptic drug-use constitutes a unique speculation on the idea of human survival through affective modification and biochemical manipulation in ways that intersect posthuman and speculative thought. In brief, and as an overarching generality, this essay aims to demonstrate how the brutal world of Fallout posits human survival via becoming- 
inhuman, or as Malins (2004) writes on the affective assemblage of organism and drug, the "continually forming connections with other bodies... which have the capacities to transform bodies" (p. 89).

In an oft cited section of $A$ Thousand Plateaus, Deleuze and Guattari (2007) levy the Artaudian term Body without Organs $(\mathrm{BwO})$ as a critical practice against those transcendent laws or schemas that would seek to pattern and manage bodily flows and their potentials for becoming and transformation. In its familiar deployment within $A$ Thousand Plateaus (1987), Deleuze and Guattari mobilize the question of how the body is composed in the first place, advancing the $\mathrm{BwO}$ as experimental practice or "set of practices" for remaking a body that is always actual-virtual (p. 150). Referencing Spinoza's Ethics as the "Great Book of the BwO", Deleuze and Guattari mobilize the assertion that we do not yet know what a body can do. Of specific concern here is the overdetermination of the body through the prior arrangement of its organs. For its modulation of the very conditions under which a body might survive, the postapocalyptic wastelands of Fallout demand what Deleuze and Guattari dub the $B w O$, which might here be understood as an entreaty to experiment with the body and its capacities to act and be acted upon. It is in this manner that Deleuze and Guattari refer to the $\mathrm{BwO}$ as a 'practice', or rather, as something that must first be made whose stakes involve the very question of "life or death" (p. 151).

Where Deleuze and Guattari's BwO figures as a vehicle for reimagining bodily flows by attending to its immanent capacities for connection and disconnection, Fallout posits for the player a similar potential reconfiguration of the virtual body (henceforth written as 'body') via the affective flows of biochemical modifiers and access to altered states and capacities. This externalization of the body, or rather, its imagined openness to what it is not constitutes a hallmark of the posthuman imagination, here minimally articulated through the connection of the body to both the cybernetics of Fallout's in-game "Pipboy" Heads Up Display (HUD) and so too those pharmacological compounds through which the body enters into affective states necessitated by the vicissitudes of survival. The post-apocalyptic $B w O$ dramatized in Fallout articulates as an aspect of survival the body's potential to enter into affective states 'unnatural' to the organism. Put differently, Fallout dramatizes a mode of arranging the body qua survival that considers the inadequacies of its natural, basic capacities and necessary rearrangement alongside the affective powers of biochemical modifiers. This is to say that the world of Fallout is an experiment with the survival of the organism by both thinking and remaking the composition of its body. Herein, Fallout experiments with the question of what a body can do, in part by examining how the survival of the normative and bounded body is foreclosed by a world that recedes from our familiar image of the world for-us (Thacker, 2011). While the post-apocalyptic world of Fallout makes no imposition on the player to modify the abilities or affective capacities of the body through drugs, survivability without the radiation mitigating drug $\mathrm{Rad}-\mathrm{X}$, radiation treatment Radaway, damage reducing opioid Med-X, or curative Stimpack is dubious, albeit not impossible. While the $\mathrm{BwO}$ dramatized in Fallout considers how the body and its survival might be achieved by assembling with drugs, it postulates other ways of creating the post-apocalyptic body, such as its technological manipulation via implants, or its shielding within biologicallyenhancing power armor. While this essay focuses on the particular relationship between 
drugs and survival dramatized within Fallout's, biomodification through drug-use is but one answer to the virtual problem of how one might survive the post-apocalyptic future. Where each of these attempts to modify the body and its capacities coincide is within Fallout's ontological gambit that the survival of the human species requires its pliable recreation as more-than-human.

\section{The Pliable Body}

The ruined world of Fallout commences with an image of the virtual body open to the potential of biological hacking. At a most rudimentary level, damage incurred by the player-character is remedied by the intravenous use of Stimpack, which while selected through the Pip-Boy HUD, appears discreetly within the game as a rudimentary syringe injection system audibly registered by the sound of a brief air blast and visually as an immediate increase in health points. Also dispensed via syringe, the opioid analgesic $M e d-X$ functions to block pain receptors and hence to allow the player-character to be less affected by damage as Health Point (HP) loss. Herein, Fallout dramatizes survival through the mediating potential of pharmacological treatment, and in this sense, differs little from a plethora of games that utilize supplementary objects to augment health. What is compelling, if not equally familiar about Fallout's dramatization of survival, is its demonstration of the body 'affected' by drugs, where for example, the organism's connection to Stimpack augments its vitality, or in the case of Med-X, to be less affected by the challenges of a hostile world. Such video-game conventions are uniquely reshaped in Fallout, which posit a fundamentally different understanding of survival via the manipulation of the body's thresholds and endurance. That is, within the hostile ecology of Fallout's post-nuclear earth, it is the pliability of the body and its receptiveness to chemical reengineering that constitutes a condition of future survival. Herein, the very nature of the 'survivable' body is rethought as an object that must again be made, yet this time in relation to a planet that demands different affective capacities commensurate with survival.

\section{Life on 'Chems'}

The post-apocalyptic BwO of Fallout's player-character protagonist 'Lone Wander' ('Courier' in Fallout: New Vegas and 'Sole Survivor' in Fallout 4) is composed in relation to a litany of 'chems', and herein Fallout reiterates as a condition of survival the fluidity of the body modulated by drugs. For example, Buffout, a pre-war super-steroid used by athletes, vastly alters the player-character's ability to be affected by buffeting health points and so too, the character's affective capacity to do harm. In distinction, Mentats, a pre-war cognitive enhancement pill, modulate the intelligence of the playercharacter, increasing affective potential along a specific line of complex tasks from computer hacking to persuasion. The pre-war military enhancement drug Psycho similarly alters the affective powers of the player-character, yet this time by enhancing resistance and increasing affective capacities to do damage. For their affective function,

Fallout's post-nuclear pharmacopeia is a way of recreating the body by experimenting 
with its capacities for transformation. While the 'drugged body' appears within the PipBoy HUD as a blissed-out or 'wasted' Vault Girl/Boy, this icon belies the multiplebodies postulated within Fallout's mis-en-scene of post-apocalyptic survival. That is, the assemblage of organism and drug dramatized in Fallout enables a variety of biochemically hacked bodies including - by way of brief demonstration - the altered perceptual time induced by Jet, the psychotic invulnerability catalyzed by Psycho, or Buffout's distorted thresholds of strength. This is to imagine the assemblage of organism and drug along different instantiations of the $\mathrm{BwO}$, each with their particular affective qualities to act and be acted upon.

\section{The Pharmacological Sensorium}

The affective assemblage of organism and drug thought via the fluid body of the 'Lone Wanderer' (LW) is registered in a multitude of ways, from its most basic alteration of character statistics in the Pip-Boy HUD, its modification of the player-characters' affective relation to objects in-game, and most significant to this essay, the transformation of the players' perceptual relation to the game itself. It is this latter aspect by which the player itself registers the affective experience of Fallout's pharmacopeia. Effects range from greater persuasive acuity in dialogue and attractiveness to other characters (Grape Mentats, for instance) and ability to access in-game pathways otherwise blocked by computer terminals, locked doors, or deadly booby-traps. More interesting still are the effects of drugs like Jet, which are registered through the affective deceleration of game-time which is of course also the acceleration of the playercharacter's perception of reality and motor physiology. Jet enables the player to both apprehend its environment with accelerated immediacy while allowing access to its

affective qualities. By accelerating camera movement and decelerating the movement of objects and audio, the player minimally experiences Jets' hyper-stimulated sensorium. The affects of Jet further enable the player to experience non-normal perceptual experiences of space-time by unfettering the camera from its 'standard' speeds and by visually inducing its amphetamine-hyped tempos. A distinct affective experience is registered with the use of the military-engineered Psycho, most notably in the distorted perception of your own coarse, death-metal battle-cry, "Rar! Bring It" and "Fucking Kill!'. Psycho's modification of the player-character's voice again deregulates the standard affective recognition of the LW's predominantly calm and oft-critiqued 'affectless' enunciation. This shift in the registration of the player-character's voice is significant, at face value for its affective articulation of Psycho's ultraviolent frenzy, but particularly so for its dramatization of the different perceptual registers beyond the 'human' made possible by the post-war pharmacopeia and necessitated by the abominable conditions of post-nuclear earth. Fallout's disarticulation of the game's 'standard perception' is also compelling from a posthuman 'perspective', which in some iterations submits that the future of the human species is predicated on its ability to differ from itself, or less obliquely, to become, both conceptually and physiologically, something other than human (Colebrook, 2013). The modulation of the player's perception and ability of the player-character to affect other bodies through drug use is both a speculation on how different affective modes might be required to survive post- 
apocalyptic ruin, and an experimental postulate on ways human sense and affect might be altered adequate to the new earth upon which the LW awakens.

\section{Post-Apocalyptic Pharmakon}

Drug experimentation is, or course, not without its risks. To gloss Derrida's (1981) developments on the pharmakon, every cure is a poison, and for the delirious enhancements associated to drugs in Fallout, there is the potential for 'bad trips' (p. 65). However, as Fallout remits, the risk of using drugs is often related to moral values we might imagine obsolete in the post-nuclear context, such as when the staunchly conservative 'butler' Codsworth 'dislikes' the LW's drug use, anxiously querying '[f]eeling a bit knackered, are we, Mum?'. As Malins articulates, drug-use is 'connected back up to the social machines of public health or medicine or morality through which it becomes stratified as a 'drug user' or 'addict' or 'deviant' respectively" (Malins, 2004, p. 88). Yet, while most would-be companions of the LW eschew drug-use, they don't 'dislike' it, where the 'dislike' mechanic functions to affect companion affinity and access to special dialogue options and skills. The prime caveat here is that the mechanics of Fallout attribute a probability that the LW will become 'addicted' to chems, a transgression that some would-be companions do 'dislike'. Drug addiction attributes minor penalties to character traits, but is easily enough cured by wasteland physicians, widely-available Addictol, by cooking and ingesting Radscorpion egg omelette, or crafting a Refreshing Beverage made from antiseptic, blood, purified water, Radaway, and Stimpack. While there is general antipathy toward the use of drugs by would-be companions, Fallout nonetheless habilitates a nervous acceptance of the modifiable body through drugs, doubly demonstrated through the variety of cures available to the drugaddicted LW. It is in this way Fallout attends to the paradox of drug use as both a cure and poison. Yet, for its diminished treatment of drugs' negative consequences, Fallout articulates their transformed status in the post-apocalyptic milieu, for the threshold of companion affinity is not related to the use of drugs, but habitual dependency on them. Against the habit of repetition then, Fallout once again affirms 'remaking the body' but with caution regarding its thresholds. Interestingly, it is when the LW becomes overcoded by drugs via addiction that Fallout attributes negative affect in the form of statistical and in-character consequence. This reiterates a concurrent, yet paradoxical thematic that postnuclear survival is optimally met with a fluid body not yet captured in either habitus or habit. This is to habilitate a nomadic body capable of traversing the wastes and so too its own alchemical non-standard chemical recomposition.

\section{Designer affects}

As much as Fallout portends a future in which the idea of the body as bounded and stable is superseded by a highly experimental approach to the composition of the body and its affective capacities, it is concomitantly an augury on the implicit manipulation of the body by the industrial precursors of the Anthropocene, namely, the military-industrial 
complex (Psycho), hyper-masculinized agon of sport (Buffout), and industries of cognitive capitalism (Mentats). It is here that Fallout reveals, in part, the affective commitments of pre-apocalyptic society, which is also to implicate those dominant affective modes that ultimately propelled the world into ruin. As the planet recedes from anthropomorphic benevolence, it is no leap to identify today the perpetuation of misery in the forms of military aggression, combative negation, and cognitive submission to interminable flows of information. Fallout's epitaph 'War Never Changes' herein assumes new significance in that the majority modes of pharmacological becoming available to the LW are genetically linked to the pre-war industrial complex and its manipulation of the body's affective registers and capacities to act.

Fallout commences upon the continuation of war not only in its overt dramatization of an inherently confrontational world of opposition and negation, but at the molecular level where the LW is biochemically altered along affective corridors commensurate with the very mis-en-scene of warfare and survival. Herein, the body is not simply enjoined to drugs, but to a particular matrix of affective potentials in which the capacity for 'war' is 'molecularly' repeated. Fallout's speculative dramatization of future survival imagines as an ultimate reference the delimited affective potential of the body as it might best be adapted to a hostile post-apocalyptic reality. In this delimitation of affects to the designer effects of pre-war drugs, Fallout perpetuates the idea of war actualized at both macro and molecular scales of existence.

While Fallout conjectures on how the post-apocalyptic body is shaped in relation to its pre-war industrial and institutional complexes, it also functions a precursor to a revolution in biomodification. That is, Fallout rethinks the pre-war pharmacopeia through DIY pharmacological practices, alchemy and 'cooking' immanent to the irradiated flora and fauna of a post-nuclear planet. Here, Fallout speculates not only on the necessity to rethink modes of biomodification immanent to climatological catastrophe, but of machining the body delinked from investments in prior forms of affective conditioning. Smooth Operator, Grape Mentats, and Skeeto Spit for instance, are each fabricated from the post-nuclear ecology for varied purposes intimate to wasteland survival.

\section{Experimenting on the body}

While Psycho and Buffout affected bodies rejoin the ideals of biomanipulation imagined by pre-war society, Fallout equally imagines the acceleration of drug induced affects through, for instance, the combinatorial crafting of Psychojet, Psychobuff, Buffjet, Bufftats, and such craftable post-apocalyptic drugs as Fury, Jet Fuel, Overdrive, and Ultra Jet. The scope of biochemical alterants craftable in the post-war context marks an important divergence from pre-war ideals regarding bio-chemical modification. That is, while Fallout lore connects drug use to the specific industries of militarism, sport, and leisure, post-apocalyptic drug use eclipses such compartmentalization for the fact that future survival becomes predicated on immanent proficiency in any number of areas including computer hacking, lock-picking, combat proficiency, or heightened awareness of environmental dangers. In this way, the drugged body is less coded by industrial ideals of body modification (the hyperagressive affects of Psycho, for instance), becoming 
instead a potential answer to a host of virtual problems that might be faced in a postapocalyptic survival scenario. The use of combinatorial chems like Bufftats dramatize how modes of body modification are disconnected from their pre-war milieus of use and combined against a backdrop that no longer selects, for instance, either the strong or smart, but the immanent becoming of strong and smart. This idea is accelerated further with post-apocalyptic drugs like UltraJet, which breaks the LW from its 'human' experience of duration by stretching time through audio-visual deceleration. Binary thinking becomes obsolete and such obsolescence pertains not only to LWs becomingmolecular, or rather, its connection with inhuman chemical bodies, but more potently, its thinking about the connection between survival and the machinic or connective body. While the LW is drawn into a particular pre-formulated narrative that gives identity in advance, such as with the insertion of the player into the familial melodrama of Fallout 4, such narrative stability is betrayed by the drugged body, which destabilizes identity in revealing the 'true' ontological mode of survival espoused in the game. That is, in the post-apocalyptic wastelands of Fallout, identity always runs parallel to its mutation, to altered states, and non-standard modes of perception and affect that survival is thought to require.

\section{Better Living Through Chems}

Dramatizing the relationship between bodily potential and its imbrication with pre-war industries, Fallout parallels the 'dark' posthumanist conceptualization of the body as it is imbricated today with a variety of perilous ecological realities. As reports on climate change increasingly suggest, human life is today interconnected with such ecological problems as carcinogenetic industrial effluent, the bioaccumulation of synthetic hormones, antibiotics, heavy metals in food and water, and the proliferation of potentially toxic micro-plastics across the biosphere. The growing realization of our material imbrication with the environment is dramatized throughout Fallout's registration of environmental radioactivity and post-nuclear radioactive weather patterns upon the LW. The ingestion of most food and water similarly registers an increase in radioactivity audibly registered by the sound of an active Geiger counter. Importantly, Fallout begins with the idea of the body's open relationship to its hostile environment. The LW might no longer be the 'bounded man' of the modern era, stalwart against the surroundings it aimed to master, but as speculatively wed in passive porous relation to its ecology. Here, Fallout seems prescient for its dramatization of our current ecological situation and its supposition that notwithstanding the vaunted anthropocentrism and heroic masculinities endemic of the modern era, the human was always open to its 'outside'.

Fallout is, of course, not solely a speculative vehicle, reflecting directly as it does the conditions of contemporary survival, where it is already reported that $70 \%$ of all Americans' take legal prescription drugs to seemingly improve but definitively alter their lives through biochemical manipulation. Fallout 4's 'Massachusetts's Surgical Journal' reiterates of the present biomedical idea of 'better living through chems' and its intersection with the utopian images of the 'good life' and bourgeoisie status quo. In compelling ways, Fallout delinks the conflation of drugs with such 'standard' images of desire by negating the very potential of utopia. The game accomplishes such negation by 
demonstrating in a manner corollary to the post-structuralist incredulity toward metanarratives how ostensibly utopian aspirations often inhere a dystopic impulse (Lyotard, 1984). Today, such a realization is already upon us, where for many, biochemical manipulation is a requirement to 'survive' and adapt to the requirements of an increasingly uncertain world that meets such uncertainty with demands of conformity and standardization. Fallout disabuses us of the notion that the majority values of contemporary Western life will be adequate in the after-Earth, when the planet will no longer reflect in the mirror of human desire. Fallout speculates that the biochemically modified body will constitute a significant ontological mode of post-apocalyptic survival, with the caveat that the drugged body is only one way in which the problem of survival might be answered. Importantly, Fallout's divestment of the drugged body from its imbrication within the social ideals of the present returns to the body to its immanence and capacity to act differently disabused of transcendent regulation where, for example, the use of mood stabilization drugs have come to reflect in the continued Western social aspiration for 'happy affects' and happiness now compulsory in so many social spheres (Scranton, 2015). At the core of its survival mechanics, Fallout returns the body to the plane of experimentation or $\mathrm{BwO}$, whereupon the body might be reconfigured and remade after the human, or at least the image of the 'standard' human born into the 'givenness' of social relations. And while Fallout's algorithms already circumvents the BwO by delimiting modes of becoming, what remains interesting is Fallout's speculative idea that survival might require a radical rethinking of the body's capacities for transformation against its radically changed ecological background.

\section{Fabulating Future-Life}

Fallout might be an interesting fulcrum upon which to think about the re-launch of life through artistic fabulation (Wallin, 2011, p. 105). This rejoins us to contemporary trajectories of climate change which in many ways supposes new modes of becoming. Throughout the world of Fallout, the body is returned to the event of becoming and made into a medium for radical bio-artistic practice. That is, given Fallout's focus on the transformation of affect catalyzed by the organism/drug assemblage, the game itself becomes $a$ way of experiencing the myriad relations into which the post-apocalyptic body might enter. In albeit limited ways, Fallout habilitates the idea of the body as an artistic material open to mutational difference through bio-hacking. It is here that Fallout not only speculates on the survival of the body through dark molecular revolution, but asks again, in the face of post-apocalyptic civilizational ruin, what a body might sustain to survive. In this, Fallout commences a compelling aspect of bio-artistic practice articulated by such artists as Yang Zhichao and Marion Laval-Jeantet and their biochemical assemblage with such nonhuman bodies as grass and horse blood. That is, the body of Fallout's survivor is no longer human in its standard sense, but rather, a 'machine' in the sense of its potential to connect with other 'bodies' of the dark posthuman wasteland. It is to this very scene that we today turn in asking again what kinds of relations might be habilitated to ensure the survival of the human species. Fallout's conclusion, which is realized by way of its thinking through bio-modifiable and inhuman affective potentials of the body is incisive: There is no survival of the human 
proper, but in its place, the potential for a non-standard human born from an experimentation with its affective thresholds and ontological composition.

\section{References}

Colebrook, C. (2013). Death of the posthuman: Essays on extinction, vol. 1. Ann Arbor, MI: Open Humanities Press.

Deleuze, G. \& Guattari, F. (1987). A thousand plateaus: Capitalism and schizophrenia vol. II. Minneapolis, MN: University of Minnesota Press.

Derrida, J. (1981). Dissemination. Chicago, IL: University of Chicago Press.

Genosko, G. (2002). Felix Guattari: An aberrant introduction. New York: Continuum.

Lyotard, J. F. (1984). The postmodern condition: A report on knowledge. Minneapolis: MN: University of Minnesota Press.

Malins, P. (2004). Machinic assemblages: Deleuze, Guattari and an ethico-aesthetics of drug use. Janus Head, 7(1), 84-104.

Scranton, R. (2015). Learning to die in the anthropocene. San Francisco: City Lights Books.

Thacker, E. (2011). In the dust of this planet: Horror and philosophy vol. 1. Washington, DC: Zero Books.

Wallin, J. J. (2011). Mobilizing powers of the false for arts-based research. Visual Arts Research, 37 (1), pp. 105-111. 